\title{
Examining Colleges of Education Mathematics Tutors' Conceptions in Teaching Completing the Square in Ghana
}

\author{
Mohammed Nurudeen Alhassan ${ }^{1}$, Douglas Darko Agyei ${ }^{2}$ \\ 1 Department of Mathematics and ICT, OLA College of Education, Ghana. \\ ${ }^{2}$ Department of Mathematics and ICT, University of Cape Coast, Ghana
}

DOI: 10.29322/IJSRP.10.03.2020.p9927

http://dx.doi.org/10.29322/IJSRP.10.03.2020.p9927

\begin{abstract}
The objective of the study is to understand colleges of education tutors' conceptions in teaching completing the square in an effort to design an innovative teaching strategy that could impact positively on their knowledge, skills and practices in teaching completing the square. It was conducted among a conveniently sampled 46 tutors from twenty three (23) colleges of education in Ghana under a mixed method design, combining both quantitative and qualitative approaches in the data collection and analysis. Tutors were presented with a questionnaire made up of 46 items presented in three parts. Based on the analysis it can be concluded that colleges of education tutors conception of teaching completing the square is very weakly grounded in procedural knowledge (i.e. use of rules), but failed to demonstrate conceptual understanding of the rules and processes of completing the square. It is recommended that a refresher course be organised to equip colleges of education tutors with innovative and practical ways of teaching completing the square in ways that are efficient and practical to facilitate their conceptual understanding of the rules and processes.
\end{abstract}

Index Terms- quadratics, procedural fluency, conceptual understanding, colleges of education, completing the square

\section{INTRODUCTION}

$\mathrm{M}$ athematics education researches show that students' performance in quadratic equations in most cases is very low and does not increase to a noticeable degree even after teahing (Chaysuwan, 1996; Vaiyavutjamai et al., 2005). This notion could partially be due to the fact that, tutors pedagogical content knowledge is not sufficient to select and use innovative teaching strategies to offer students desired learning experiences that could impact positively on learning outcomes. The concept of quadratics cannot be over emphasised as it lays the foundation for higher order polynomials (Sağlam \& Alacac1, 2012). In spite of the merits of quadratics in senior high school, colleges of education and prescribed mathematics contents, the studies on colleges of education tutors conceptions in teaching completing the square in literature is limited, since a few studies on the teaching and learning quadratics have been conducted (Kieran, 2007; Vaiyavutjamai \& Clements, 2006; Didiş et al., 2011; Didiş $\&$ Erbaş, 2015). Teaching mathematics in most colleges is often centred on the use of rules and formulas to develop pre-service teachers' procedural fluency rather than teaching them for conceptual understanding (Sarwadi \& Shahrill, 2014). Other tutors often teach quadratics using rigorous algebraic method, where pre-service teachers are taught how to complete a given square, without necessarily knowing why such procedures work. It is for this reason that a study has to be conducted among colleges of educations tutors to understand their conceptions in teaching completing the square which to a large extend could be influencing the outcomes of those that they teach, or perhaps they are simply passing on to their students what was taught to them by the universities that train them.

Pre-service teachers who are taught effectively are expected to demonstrate both conceptual understanding and procedural fluency. Conceptual understanding is the kind of understanding that is influenced by logical and foundational thought upon which a concept is developed. Conceptual understanding brings to bare inherent relationship, or provides justification for actions taken in an attempt to solve a problem. Such understanding is described as that which is interconnected through relationships upon a careful observation of commonalities (Confrey, 1990). Conceptual understanding is much desired in the learning of mathematics than procedural fluency, even though a clear cut caurse and effect relationship has not been established. It is important for pre-service teachers to develop their conceptual understanding, as the absence of it could result in wrong processes and products (Center for Develop Enterprise, 2007).

Zemelman, Daniels, and Hyde (1998), stated that improper grabs of concepts has the potential of hampering the learning of other concepts. Pre-service teachers who are grounded in conceptual understanding are motivated to succeed in acquiring further skills in learning mathematics. Tutors are expected to show demonstrable knowledge of their students' mathematical thoughts to be able to choose and organise their teaching to meet the learning styles of their students. This is hampered if the tutors are deficient in conceptual understanding. These tutors are forced to pass on ideas to their students, hock, line and sinker without convincing explanation. The students view about concepts is influenced by how their cognitive structures were developed previously by their teachers (Battista, 2001). When pre-service teachers have weaker cognitive structures, they approach learning from a narrow sense and may fail to demonstrate acceptable competences. It is therefore important that tutors are 
grounded in conceptual understanding so that pre-service teachers under their tutelage could be taught in ways that are rich in relationships and can be extended to solve novel problems. Conceptual understanding forms the basis of procedural fluency. Tutors who are rich in conceptual understanding do not encourage rote learning, but insist on deep understanding which automatically translate into proper and justifiable procedures.

Procedural fluency is good at reinforcing understanding of mathematical concepts. Procedural fluency is the learners' ability to follow relevant procedures in solving mathematical problems in different situations (Kanyaliglue, Ipek, \& Isik, 2003; Hiebert \& Lefevre, 1986). Procedural knowledge is specific to problems and this implies that some procedures are not appropriate to solve other mathematical problems, which causes a serious deficit in pre-service teachers understanding of mathematical concepts. Pre-service teachers may demonstrate relevant procedures but sometimes gets stacked in solving mathematical problem (Siegler, 2003). Ndlovu and Brijall (2015), underscore the importance of conceptual understanding by stating that most students show weaknesses in mathematics because their learning is associated with a lack of conceptual understanding. Learners who lack procedural fluency will usually use inappropriate procedures which will often lead to systematic patterns of errors in executing completing the square. Accordingly, tutors should not only focus on developing procedural fluency as well as conceptual understanding. Failure to do so could jeopardise preservice teachers' conceptual understanding.

Riccomini (2005) explains that instruction focused on the development of facts is problematic, as it often results in partial teaching of concepts, which defeats the role of tutors in the lecture rooms. Tutors are generally trained to teach mathematics in terms of general concepts, to position pre-service teachers to solve quadratic equations/expressions. Tutors who are well grounded in conceptual understanding are more susceptible to pick and choose teaching strategies that results in substantial gain in both conceptual understanding and procedural fluency among their students, but those with procedural fluency may only be showing demonstrable knowledge in procedural fluency but less in conceptual understanding, which will ultimately impede their competencies in teaching and could curtail learners' growth in conceptual understanding as well in mathematics achievement in general. Research on colleges of education tutors conceptions of completing the square is needed if we are to understand why students perform badly in completing the square. This calls for diagnosis of colleges of education tutors competences in teaching completing the square.

\section{RESEARCH OBJECTIVE AND QUESTIONS}

The objective of the study is to understand colleges of education tutors' conceptions in teaching completing the square in an effort to effort to design an innovative teaching strategy that could impact positively on their knowledge, skills and practices in teaching completing the square. To do this a diagnostic test was conducted to understand the conceptions colleges of education tutors have in teaching completing the square in order to obtain data to answer five research questions:
1. What are the Tutors' conceptions with respect to their Knowledge, Skills and Practices in teaching completing the square?

2. How do colleges of education tutors teach completing the square?

3. How do colleges of education tutors explain why in completing the square $a x^{2}+b x$, a student has to make the coefficient of $\mathrm{x}^{2}$ unit (thus 1 )?

4. How do colleges of education tutors explain why in completing the square $\mathrm{ax}^{2}+\mathrm{bx}$, a student has to find onehalf the coefficient of $\mathrm{x}$, square the quotient, add and subtract same?

5. Is there any convergence between the quantitative results and the qualitative findings?

\section{MATERIALS AND METHODS}

The study used a questionnaire to collect data in order to understand the conceptions tutors have in teaching completing the square. It was conducted under a mixed method design, combining both quantitative and qualitative approaches in the data collection and analysis (Creswell \& Tashakkori, 2007). This mixed method design gives opportunity to collect detailed and comprehensive qualitative data in order to support the quantitative data in response to the objectives of the study. Although there are various types of mixed method research designs, this study employed the explanatory model, which contains an initial quantitative data collection procedure through a questionnaire, followed by qualitative through an open ended test items. The objective of choosing this method was to obtain a deeper understanding from the quantitative data as well as use the qualitative data to support the quantitative findings. Creswell and Clark (2007) indicated that, the explanatory design is a bistage combination of quantitative and qualitative designs. The first begins with the collection and analysis of quantitative data and the second is the collection and analysis of qualitative data. This explanatory design is to offer the researcher an opportunity to further explain a quantitative data finding.

The current study examined Colleges of Education Tutors' Conceptions in Teaching Completing the Square. The study was conducted among a conveniently sampled 46 tutors from twenty three (23) colleges of education. Convenience sampling (also known as availability sampling) is one of the non-probability sampling method collects data from population/sample who are available and willing to participate in a study (Saunders, Lewis \& Thornhill, 2012). This type of sampling procedure is particularly useful in exploring a research area in order to identify and address shortcomings as in the case of 'Examining Colleges of Education Mathematics Tutors' Conceptions in Teaching Completing the Square' so as to propose an efficient and innovative teaching strategy in the concept. Tutors were presented with a questionnaire made up of 46 items presented in three parts. The first six items collected their bio data, the second part made up 37 items on a three-point Likert Scale of which 15 items are on knowledge, 8 items on their skills and the 14 remaining items on practices in teaching completing the square. The tutors knowledge, skills and practices were in three levels: Secured was coded 1 and understood to mean what tutors already have and being used. Emerging was coded 2 and represent what 
they want to consolidate/know more about. Aspirational was coded 3 and represented what they do not have, but want to acquire, as well as use in their practices. The third part was made up of three (3) questions and tutors were required to solve or give explanation in completing the square. For each of the three questions, a coding scheme was developed according to the extent to which colleges of education tutors were able to vividly provide a solution or offer an acceptable explanation or attempted to solve or explain the problem and assigned a numerical value as shown in Table 1.

Table 1: Student Response Code Point Values on a 5-point scale

\begin{tabular}{|l|l|}
\hline Student Response Code & Point Value \\
\hline $\begin{array}{l}\text { Solved successfully/explains very } \\
\text { well }\end{array}$ & 5 \\
\hline $\begin{array}{l}\text { Correct and valid method, but } \\
\text { wrong answer/starts explanation, } \\
\text { but deviates }\end{array}$ & 4 \\
\hline Partially solved/explained & 3 \\
\hline $\begin{array}{l}\text { Reconstruct the question in order to } \\
\text { solve/explain }\end{array}$ & 2 \\
\hline wrong method/explanation & 1 \\
\hline Did not answer/explain & 0 \\
\hline
\end{tabular}

Scoring the problems on a 5-point scale allowed me to find a group average score for each problem, as well as an average score for each tutor on the three problems. These are shown in Table 2.

Table 2: Tutors' conceptions in teaching completing the square

\begin{tabular}{|c|c|c|c|c|}
\hline $\begin{array}{l}\text { Tutors' } \\
\text { ID }\end{array}$ & $\begin{array}{l}\text { If you } \\
\text { were to } \\
\text { teach } \\
\text { your } \\
\text { students } \\
\text { how to } \\
\text { complete } \\
\text { the } \\
\text { square of } \\
x^{2}+5 x+7 \text {. } \\
\text { How will } \\
\text { you do } \\
\text { it? }\end{array}$ & $\begin{array}{l}\text { In } \\
\text { completing } \\
\text { the square } \\
\mathrm{ax}^{2}+\mathrm{bx}, \mathrm{a} \\
\text { student has } \\
\text { to make } \\
\text { the } \\
\text { coefficient } \\
\text { of } \mathrm{x}^{2} \text { unit } \\
\text { (thus 1), } \\
\text { why? }\end{array}$ & $\begin{array}{l}\text { In } \\
\text { completing } \\
\text { the square } \\
\text { ax }{ }^{2}+b x, a \\
\text { student has } \\
\text { to find one- } \\
\text { half the } \\
\text { coefficient } \\
\text { of } x \text {, square } \\
\text { the } \\
\text { quotient, } \\
\text { add and } \\
\text { subtract } \\
\text { same. } \\
\text { Why? }\end{array}$ & $\begin{array}{l}\text { Average } \\
\text { performance } \\
\text { in the } 3 \\
\text { items }\end{array}$ \\
\hline 01 & 1 & 0 & 3 & 1 \\
\hline 02 & 5 & 0 & 0 & 0 \\
\hline 03 & 5 & 3 & 1 & 3 \\
\hline 04 & 5 & 0 & 0 & 2 \\
\hline 05 & 5 & 3 & 2 & 3 \\
\hline 06 & 5 & 3 & 0 & 3 \\
\hline 07 & 0 & 0 & 0 & 0 \\
\hline 08 & 5 & 0 & 0 & 2 \\
\hline 09 & 0 & 0 & 0 & 0 \\
\hline
\end{tabular}

\begin{tabular}{|l|l|l|l|l|}
\hline 10 & 5 & 0 & 0 & 2 \\
\hline 11 & 0 & 0 & 0 & 0 \\
\hline 12 & 2 & 0 & 0 & 1 \\
\hline 13 & 0 & 0 & 0 & 0 \\
\hline 14 & 5 & 0 & 0 & 2 \\
\hline 15 & 0 & 0 & 0 & 0 \\
\hline 16 & 1 & 0 & 0 & 0 \\
\hline 17 & 0 & 0 & 0 & 0 \\
\hline 18 & 0 & 0 & 0 & 0 \\
\hline 19 & 0 & 0 & 0 & 0 \\
\hline 20 & 1 & 0 & 0 & 0 \\
\hline 21 & 1 & 0 & 0 & 0 \\
\hline 22 & 5 & 0 & 0 & 2 \\
\hline 23 & 5 & 0 & 0 & 2 \\
\hline 24 & 5 & 0 & 3 & 3 \\
\hline 25 & 5 & 0 & 0 & 2 \\
\hline 26 & 5 & 0 & 0 & 2 \\
\hline 27 & 0 & 3 & 3 & 2 \\
\hline 28 & 5 & 0 & 0 & 2 \\
\hline 29 & 4 & 0 & 0 & 1 \\
\hline 30 & 0 & 0 & 0 & 0 \\
\hline 31 & 0 & 0 & 0 & 0 \\
\hline 32 & 1 & 0 & 0 & 0 \\
\hline 33 & 5 & 5 & 3 & 4 \\
\hline 34 & 5 & 0 & 3 & 3 \\
\hline 35 & 1 & 0 & 3 & 1 \\
\hline 36 & 4 & 0 & 0 & 1 \\
\hline 37 & 1 & 0 & 0 & 0 \\
\hline 38 & 5 & 0 & 3 & 3 \\
\hline 39 & 0 & 0 & 0 & 0 \\
\hline 40 & 0 & 0 & 0 & 0 \\
\hline 41 & 5 & 3 & 0 & 3 \\
\hline 42 & 5 & 3 & 0 & 3 \\
\hline 43 & 5 & 0 & 0 & 2 \\
\hline 44 & 2 & 0 & 0 & 1 \\
\hline 45 & 0 & 0 & 0 & 0 \\
\hline 46 & 0 & 0 & 0 & 0 \\
\hline Group & $\mathbf{3}$ & 1 & 1 & \\
\hline Average & & & & \\
\hline & & & 0 & 0 \\
\hline
\end{tabular}

\section{Results and Discussion}

The objective of the study is to understand colleges of education tutors conceptions in teaching completing the square in an effort to effort to design an innovative teaching strategy that could impact positively on their knowledge, skills and practices in teaching completing the square. The first part contains quantitative data were descriptive statistics is used to describe tutors' knowledge, skills and practices. The second part is organised to give an overview of the qualitative aspect on how tutors perform across the three problems. The third and final has to do with tutors' conceptions on how to teach completing the square as well as demonstrate their conceptual understanding on key stages in using the algebraic method in completing the square.

Tutors Knowledge, Skills and Practices 


\section{Table 3:Descriptive Statistics of Tutors Knowledge, Skills and Practices}

Std.

N Minimum Maximum Mean Deviation

\begin{tabular}{|c|c|c|c|c|c|}
\hline $\begin{array}{l}\text { Tutors' } \\
\text { knowledge in } \\
\text { teaching } \\
\text { completing the } \\
\text { square }\end{array}$ & 46 & 1 & 3 & 1.78 & .512 \\
\hline $\begin{array}{l}\text { Tutors' skill in } \\
\text { teaching } \\
\text { completing the } \\
\text { square }\end{array}$ & 46 & 1 & 3 & 1.90 & .592 \\
\hline $\begin{array}{l}\text { Tutors' practices } \\
\text { in teaching } \\
\text { completing the } \\
\text { square }\end{array}$ & 46 & 1 & 3 & 1.77 & .497 \\
\hline $\begin{array}{l}\text { Valid } \\
\text { (listwise) }\end{array}$ & 46 & & & & \\
\hline
\end{tabular}

In order to efficiently describe tutors' knowledge, skills and practices, variables were computed for each of them and descriptive statistics ran. It can be seen from Table 3 that the mean for each of the three items is about 2, indicating that tutors knowledge, skills and practices were at the emerging level. This shows that for each of the constructs, tutors wanted to consolidate/know more about their knowledge, skills and practices in teaching completing the square. Their level of knowledge, skill and practices are not secured enough to effectively deal with the teaching of completing. This could be as a result of a limited knowledge of the various methods and materials available for teaching completing the square or simply not skilled enough to design and implement innovative teaching strategies for completing the square or their practices are only limited to the conventional and text book prescribed algebraic method of teaching completing the square. Tutors need to move away from the conventional text book strategies to innovative teaching strategies that offer opportunities to their students to learn according to students' mode of learning. By doing so students are able to learn according to their pace and could eventually lead to in depth learning. The findings suggest that colleges of education tutors conception in teaching completing the square is limited in knowledge, skill and practices. This explains why the average performance in each sub-scale is about 2 (i.e. emerging). A qualitative analysis was conducted to get a clearer understanding of the limited tutors' knowledge, skill and practices by presenting the three questions earlier mentioned in the methodology section to tutors to respond to. The outcome is presented in the next sections.

\section{Tutors perform across the three problems}

The average performance on the three (3) problems posed is 1 (i.e. wrong method/explanation) as indicated in Table 2. That means the group average tutor conception (i.e. knowledge, skill and practices) is to offer wrong method/explanation. This is particularly worrying as this group of tutors have a minimum of a masters degree in mathematics (education or pure or applied). If those who are particularly recommended to possess content and pedagogy far in excess than what they need in practice are themselves having serious problems in the content and pedagogy of teaching completing the square, then one can understand why performance in mathematics across all sectors of our educational system in Ghana is in serious crises. This state of affairs could be attributable to the way we train our tutors. Sometimes, assumed knowledge is exaggerated. How come a tutor is able to execute a strategy but fail to explain why such a strategy works? It points to the insinuation that most of the teaching strategies used in presenting mathematical content to teacher educators end at a level of procedural fluency, but insufficient in fostering conceptual understanding. There is the need to restructure the content and scope of the training of our teacher education to include lifelong learning strategies so that tutors will persistently search for justifiable explanations to concepts that are basic, but yet challenging. Quadratics which is the basis and foundation of polynomials in higher level mathematics if weakly developed, then we can understand why performance and enrolment in mathematics and mathematics related courses are low and under subscribed in all levels of education in Ghana (Ministry of Education, 2017). The Ministry of Education Sector Analysis, (2018, page 74) on enrolment figures in STEM indicated that 'in 2015/16 academic year, across all tertiary institutions, $31 \%$ of students were enrolled in science subjects, while $69 \%$ were enrolled in the arts. When looking at just public universities and polytechnics/technical universities, these trends are quite similar, with approximately $40 \%$ enrolled in science and $60 \%$ in arts. These figures have remained more or less stagnant across a number of years, and are far from the target of having a 60:40 ratio of science to arts enrolment'.

Teacher training institutions need to relook at how mathematics educators are trained to ensure those turned out are well equipped in both content and pedagogy if we are to succeed in raising the quality of teaching and learning of mathematics across all levels of the educational ladder.

\section{Tutors conceptions on how to teach completing the square}

'If you were to teach your students how to complete the square $\left(x^{2}+5 x+7\right)$, how will you do it?' was used to identify tutors conceptions on how to teach completing the square. Out of the 46 respondents, 31 tutors attended to the task as indicated in Table 2. Of the number that attended to the task, 20 tutors $(43.5 \%)$ successfully completed the task. Two (2) representing $4.3 \%$ used correct and valid method, but wrong answer, none partially solved, two (2) representing $4.3 \%$ reconstructed the question in order to solve, seven (7) representing $15,2 \%$ used wrong method and fifteen (15) $35.6 \%$ did not answer. For those who did not, their inability to attempt the question could stem from the fact that the methods used in teaching them how to complete a square, perhaps did not make sense or create an everlasting understanding on how to complete a given square and they have since forgotten the process. One interesting thing about the approach used by those who answered the question successfully was the use of the 'rigorous algebra' or verbal symbols is rich in the use and application rules/procedures. It is a very common method in text books and among the tutors. However, this rigorous algebraic method is weak in relationships, 
fails to provide for conceptual understanding and may not be helpful in attending to non routine problems. Tutors who are good in this kind knowledge will in most cases fail to justify why such methods work or even offer convincing explanation on why they use such steps in arriving at correct answers. This suggests that once tutors have memorized and practiced procedures that they do not understand, they care less about the reasoning behind them. Such tutors demonstrate rote learning, and will fail to adopt teaching strategies that are rich in content, fail to offer pres-service teachers various modes of learning to meet their learning needs as well fail to provide for deeper understanding of concepts (relational understanding). It can be concluded that colleges of education tutors teach completing the square using rules and procedures that they cannot justify.

\section{Tutors conception on why a student has to make the} coefficient of $x^{2}$ a unit in completing the square

Table 2 shows that only six (6) tutors were able to partially explain the reason behind such a step. Such tutors only mention the reason as 'to make it a perfect square (as in Figure 1), but failed to mention that, it is done to ensure only one square is completed, and not squares or part of a square'. Analysing these responses, it is evident that the tutors lacked a clear understanding of the meaning of the steps they executed. Others just said: to enable the process work, that is the principle and 'it is also a requirement' to complete a given square (see Figure 2a, $2 \mathrm{~b} \& 2 \mathrm{c})$. These findings depict a big gap between Skemp's (1976) proposed conceptual understanding and the tutors' conceptions of teaching completing the square. The idea of providing a justification to the steps taken was not known to the tutors. They are just good at the procedural fluency level in completing the square. One tutor was able to provide a complete justification (see figure 3 ), but this could have been influenced by an informal interaction with myself and the tutor when the instrument was being developed. This finding shows a semblance of Vaiyavutjamai, Ellerton, and Clements, (2005) statement that secondary school mathematics teachers' lack of pedagogical content knowledge in quadratics as well as Didis, Baş, and Erbaş (2011) conclusion that students are familiar with rules in solving quadratics, they applied these rules but failed to justify why it is mathematically correct. It can be concluded Tutors conception on why a student has to make the coefficient of $x^{2}$ a unit in completing the square is only instrumental where they are able to execute a process, but fail to justify why such a step is important. Thus tutors' knowledge, skill and practices are instrumental but deficient in conceptual understanding of the process.

Hence it is important to equip tutors with innovative strategies that are practical, meaningful and rich in relationships so that instruction in this topic could be improved. Colleges of education tutors are not able explain why in completing the square $a x^{2}+b x$, a student has to make the coefficient of $x^{2}$ unit.

\section{Tutors conception on why a student has to find one-half the coefficient of $x$, square the quotient, add and subtract same}

This question appeared to be a difficult question to the tutors, even for those who were able complete the given square. For those who partially offered an explanation, the statement that cut across their explanation was 'to make it a perfect square' (see Figure 3). However it was expected that the complete explanation should be 'to convert it into a perfect square without altering the area of the original quadratic equation/expression'. Geometrically, it gives an impression that some aspect of the quadratic is a square, the other is a rectangle and the remaining part has an area of the constant. This explanation is illustrated below using the expression $x^{2}+b x+c$.



To convert into a perfect square, the red line divides the rectangle into two-equal halves which can be added to the existing square as illustrated below. But this does not give a perfect square yet until an additional square (red in colour) is added at right bottom corner.

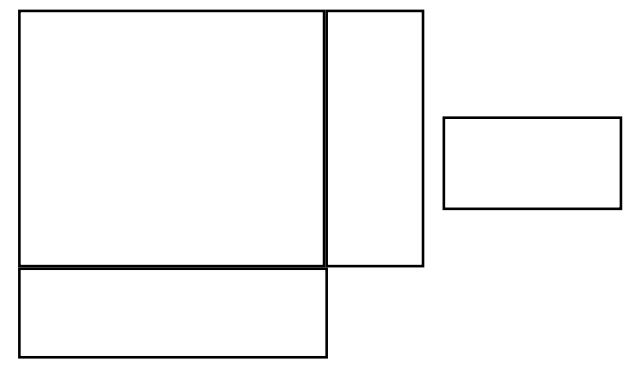

This red square has an area of $\frac{\mathrm{b}^{2}}{4}$ which increases the original area. To maintain the area it must be subtracted from the area of the perfect square $\left[\left(x+\frac{b}{2}\right)^{2}-\frac{b^{2}}{4}+c\right]$. This is simplified to $\left[\left(\mathrm{x}+\frac{\mathrm{b}}{2}\right)^{2}+\frac{4 \mathrm{c}-\mathrm{b}^{2}}{4}\right]$. Hence, the explanation that: to convert it into a perfect square without altering the area of the original quadratic equation/expression. There seems to be agreement in

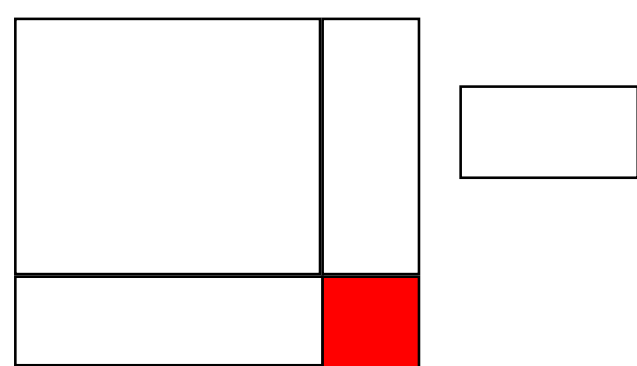

the study that tutors are using procedures without understanding and tutors have difficulties in justifying key components of the processes in completing the square. Again, this fits into Skemp's (1976) categorization that tutors are only recollecting and applying rules they do not understand. Pre-service teachers who are trained by these tutors are only developing instrumental understanding while their relational understanding is curtailed. 
This qualitative aspect was used to further gain insights into the procedure that was employed and whether they possess conceptual understanding of the process of completing the square as indicated by Shulman (1986) when he said teachers need efficient ways of demonstrating the meaning of concepts that are taught. To this end, colleges of education tutors are not able explain why in completing the square $\mathrm{ax}^{2}+\mathrm{bx}$, a student has to find one-half the coefficient of $x$, square the quotient, add and subtract same. Some extracts of tutors responses and for some selected questionss are shown below.

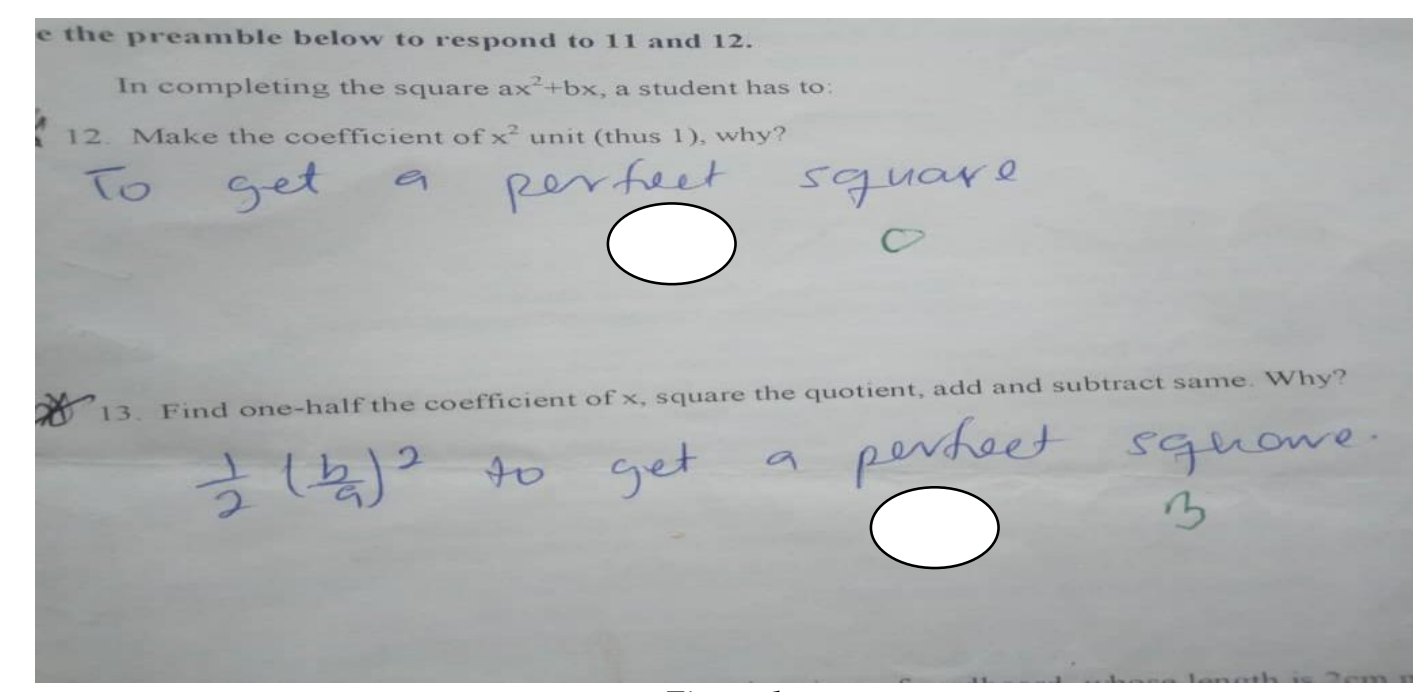

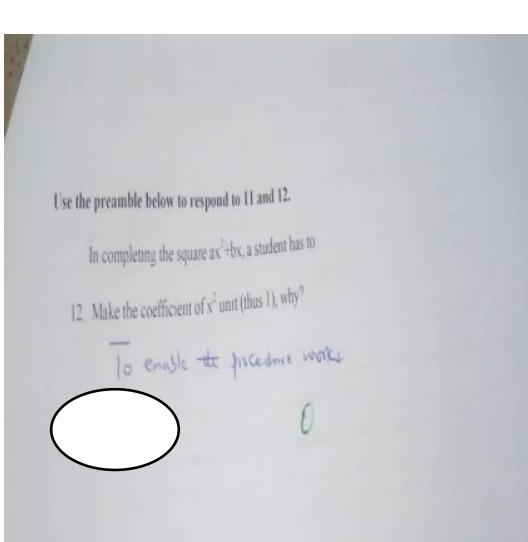

Figure 2 a



Figure $2 b$

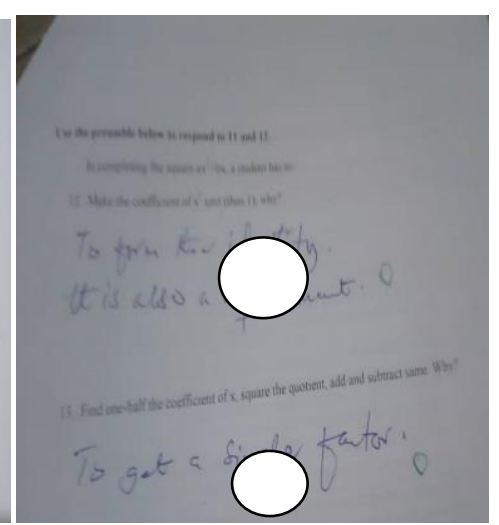

Figure 2c

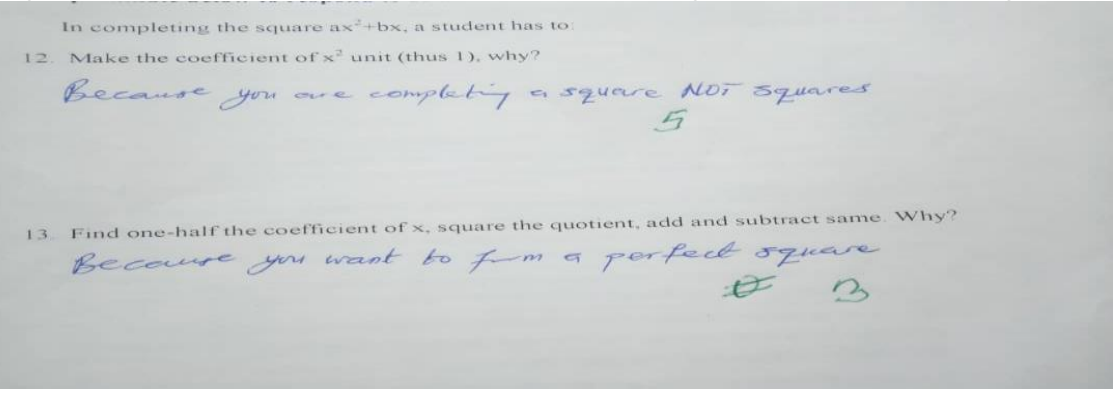

Figure 3 


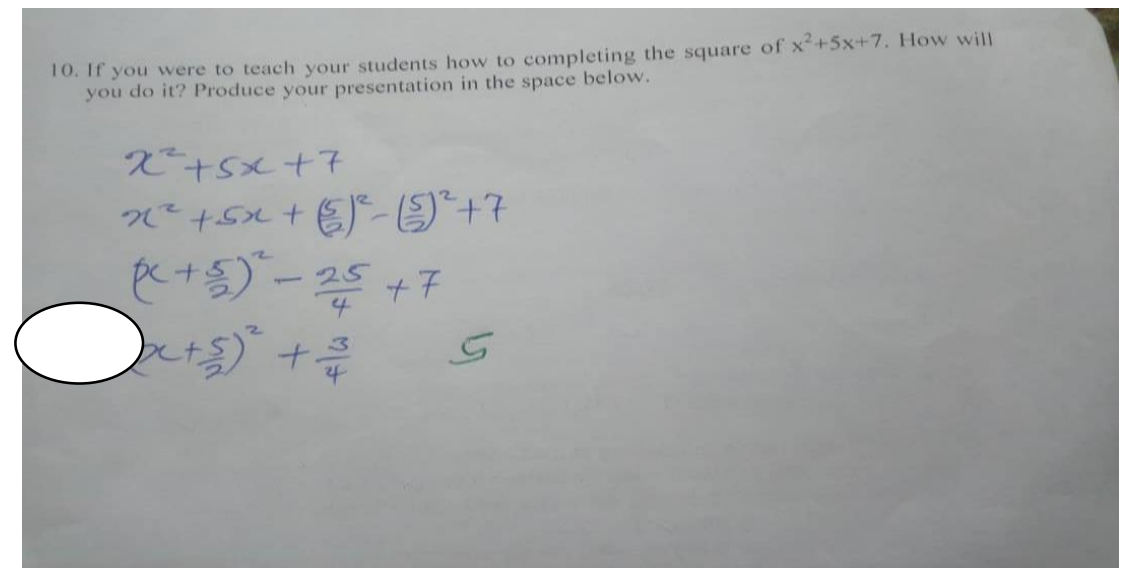

Figure 4

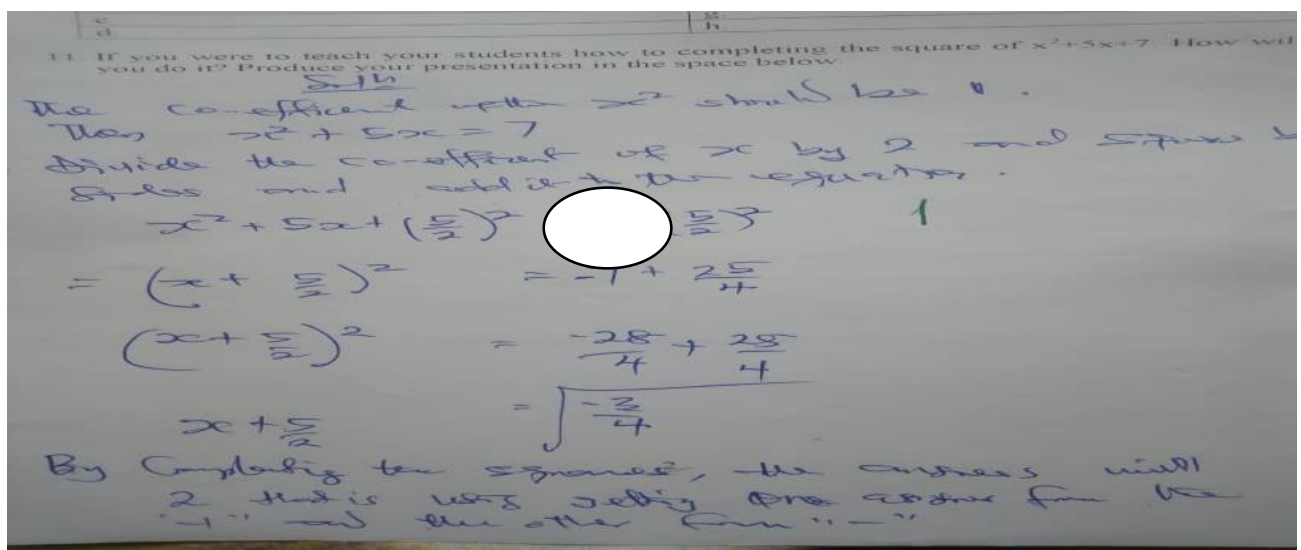

Figure 5

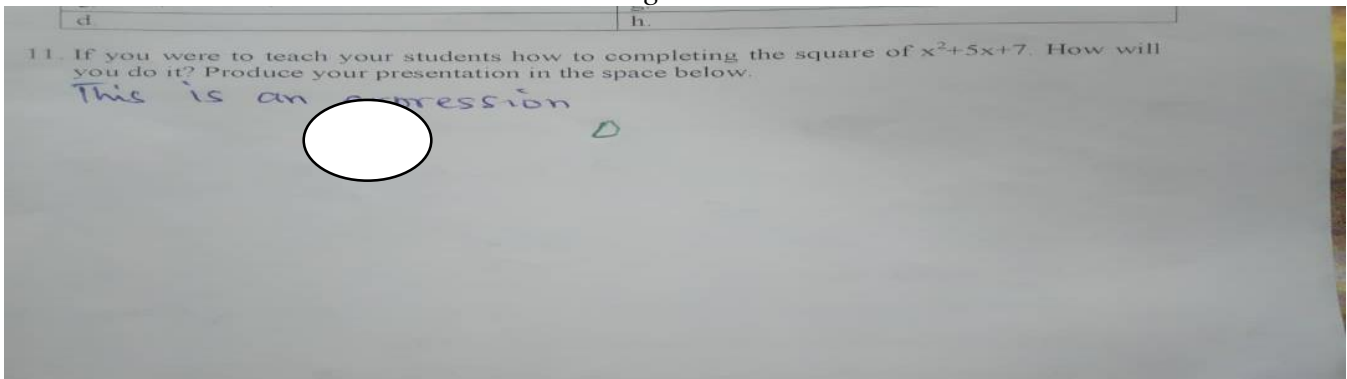

\section{Figure 6}

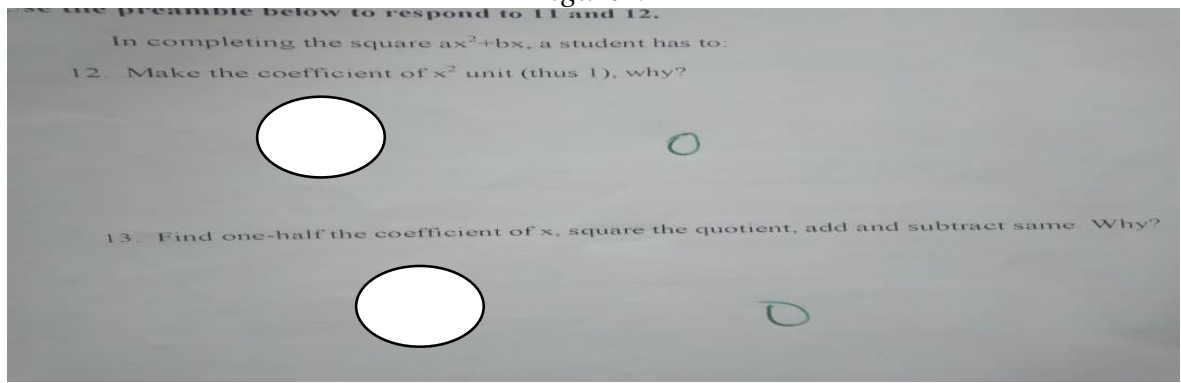

Figure 7 


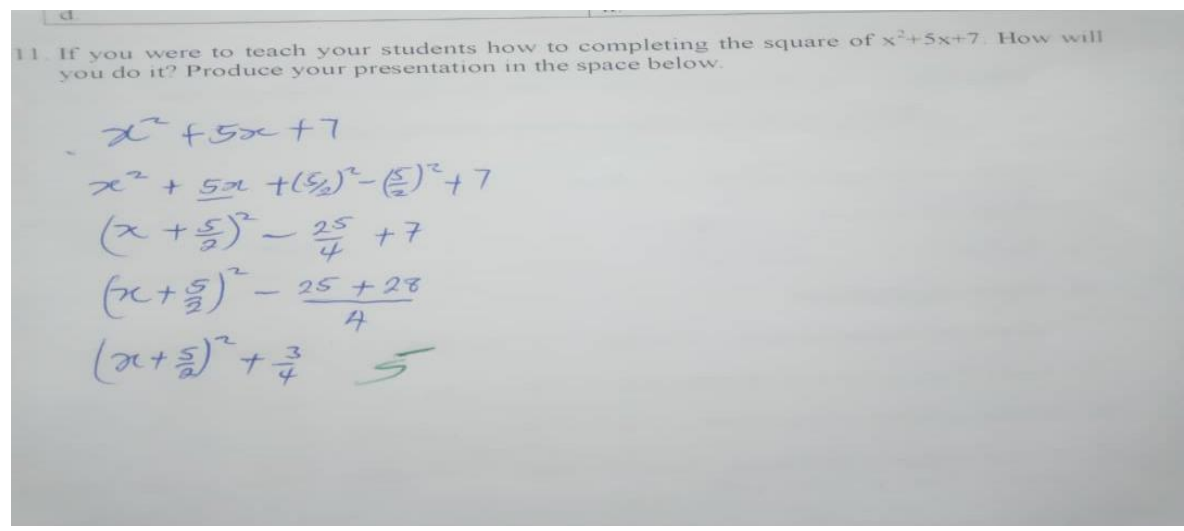

Figure 8

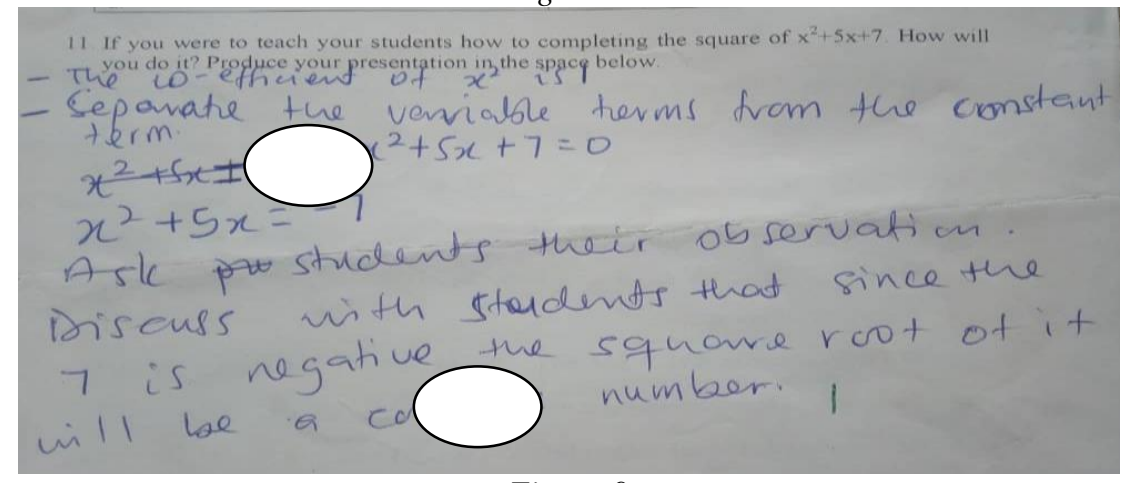

Figure 9

\section{Comparison between the quantitative results and the qualitative findings}

The quantitative analysis indicated that colleges of education tutors conception in teaching completing the square is only procedural and they have limited knowledge, skill and practices. The qualitative data leads to the conclusion that, colleges of education tutors conception in teaching completing the square is limited in knowledge, skill and practices. The qualitative analysis suggest that Tutors conception on why a student has to make the coefficient of $x^{2}$ a unit in completing the square is only instrumental where they are able to execute the process, but fail to justify why such a step is important, neither were they able to explain why in completing the square $a x^{2}+b x$, a student has to find one-half the coefficient of $\mathrm{x}$, square the quotient, add and subtract same. Comparing both the quantitative and qualitative analyses, there is seeming resemblance in the outcomes that suggest tutors lack a clear understanding and demonstration of the meaning of the steps they execute. It stands to reason that tutors conception in teaching completing the square is procedural or instrumental, rather than conceptual or relational and that both analysis leads to similar conclusion.

\section{CONCLUSION}

Based on the analysis it can be concluded that colleges of education tutors conception of teaching completing the square is very weakly grounded in procedural knowledge (i.e. use of rules), but failed to demonstrate conceptual understanding of the rules and processes of completing the square.

\section{RECOMMENDATION}

It is recommended that a refresher course be organised to equip colleges of education tutors with innovative and practical ways of teaching completing the square in ways that are efficient and practical to facilitate their conceptual understanding of the rules and processes.

\section{REFERENCES}

[1] Battista, M. T. (2001). A Research-based Perspective on Teaching School Geometry. In J.

[2] Brophy (Ed.). Subject-specific instructional methods and activities, advances in research on teaching. (Vol. 8), (pp. 145-185). Elsevier Science.

[3] Centre for Development Enterprise (CDE, 2007). Doubling for Growth: Addressing the maths and science challenges in South Africa. Centre for Development Enterprise.

[4] Chaysuwan, S. (1996). The construction of a diagnostic test on basic knowledge of algebra for Mathayom Suksa three students in the Bangkok Metropolis. Unpublished M.Ed thesis, Kasetsart University, Thailand.

[5] Confrey, J. (1990). A Review of the Research on Student Conceptions in Mathematics, Science and Programming. In C. B, Carden (Ed), Review of Research in Education. Washington: American Educational Research Association

[6] Creswell, J. W., \& Plano Clark, V. L. (2007). Designing and Conducting Mixed Methods Research. Thousand Oaks, CA: Sage Publications.

[7] Creswell, J. W., \& Tashakkori, A. (2007). Developing publishable mixed methods manuscripts. Journal of Mixed Methods Research, 1, 107-111.

[8] Didis, M. G., Erbas, A. K. (2015). Performance and Difficulties of Students in Formulating and Solving Quadratic Equations with One Unknown. Educational Sciences: Theory and Practice, Vol. 15, No. 4, pp. 1137-1150.

[9] Didis M. G., Baş S., Erbaş A. K. (2011). Students' reasoning in quadratic equations with one unknown. Paper presented at the 7th Congress of the European Society for Research in Mathematics Education. 2011. Retrieved 



http://www.cerme7.univ.rzeszow.pl/index.php?id=wg3,

[10] Hiebert, \& Lefevre, P. (1986). Conceptual and Procedural Knowledge in Mathematics: An Introductory Analysis. In J. Hiebert (Ed), Conceptual and Procedural Knowledge: The Case of Mathematics. pp. 1-27. Hillsadale, NJ: Erlbaum.

[11] Kanyalioglu, A. C., Ipek, A. S., \& Isik, A. (2003). On the teaching linear algebra at University level: The role of visualising in the teaching vector space. Journal of Korea Society of Mathematics Education Series D. Research in Mathematics Education, 7(1), 59-67.

[12] Kieran, C. (2007). Learning and teaching algebra at the middle school through college levels. In F. Lester (ed.), Second Handbook of Research on Mathematics Teaching and Learning: A project of the National Council of Teachers of Mathematics. Vol II (pp. 669-705). Charlotte, NC: Information Age Publishing.

[13] Ministry of Education,(2017). Medium Term Expenditure Framework [MTEF] for 2017-2019. Ministry of Finance, Accra.

[14] Ministry of Education, (2018). Education Sector Analysis 2018. Ministry of Education, Accra.

[15] Ndlovu ZA, Brijlall D 2015. Pre-service teachers' mental constructions of concepts in matrix algebra: A South African case. African Journal of Research in Mathematics, Science and Technology Education, 19(2): 1561711

[16] Riccomini, P. J. (2005). Identification and remediation of systematic error patterns in subtraction. Learning Disability Quarterly, 28(3), 233-242.

[17] Rule, P. and John, V. (2011). Your Guide to Case Study Research. Pretoria: Van Schaik Publishers.

[18] Sağlam, R., \& Alacaci, C. (2012). A Comparative Analysis of Quadratics Unit in Singaporean, Turkish and IBDP Mathematics Textbooks. Turkish Journal of Computer and Mathematics Education, 3(3), 131-147.
[19] Sarwadi, H. R. H., Shahrill, M. (2014). Understanding students' mathematical errors and misconceptions: The case of year 11 repeating students. Mathematics Education Trends and Research, 2014, 1-10

[20] Saunders, M., Lewis, P. \& Thornhill, A. (2012). Research Methods for Business Students. $6^{\text {th }}$ edition, Pearson Education Limited.

[21] Siegler, R. S. (2003). Implantation of Cognitive Science Research for Mathematics Education. Carnegia Mellon University. In Kilpatrick. Sorensen, A. (2003). Effective Teaching high School Mathematics.

[22] Vaiyavutjamai, P., \& Clements, M. A. (2006). Effects of classroom instruction on students' understanding of quadratic equations. Mathematics Education Research Journal, 18(1), 47-77.

[23] Vaiyavutjamai, P., Ellerton, N. F., \& Clements, M. A. (2005). Students attempts to solve two elementary quadratic equations: A study in three nations. $\quad$ Retrieved January 22, 2020, from www.merga.net.au/documents/RP852005.pdf.

[24] Zemelman, S., Daniels, H., and Hyde, A, (1998). Best Practice: New Standards for Teaching and Learning in America's Schools (2nd ed.). Portsmouth, NH:Heineman.

\section{AUTHORS}

First Author - Mohammed Nurudeen Alhassan, Department of Mathematics and ICT, OLA College of Education, Ghana Second Author - Douglas Darko Agyei, Department of Mathematics and ICT, University of Cape Coast, Ghana 